\title{
DIGITAL CITIZENSHIP IN THE RUSSIAN FEDERATION: POLITICAL RISKS AND PROSPECTS
}

\author{
Ivan A. Bronnikov \\ Lomonosov Moscow State University, Moscow, Russian Federation \\ Victoriya V. Karpova \\ Digoria Forum of Young Political Scientists of Russia, Moscow, Russian Federation; \\ Lomonosov Moscow State University, Moscow, Russian Federation
}

\begin{abstract}
Introduction. The realities of modern society reflect the demand of science to understand, explain and stage the structural transformations of the political process of a digital nature. Civic Internet activity is acquiring non-hierarchical forms and is ahead of technological practices used by the state. Introducing themselves into the modern political process, network organizational structures allow the formation of strong horizontal ties, acting as a tool for accumulating public opinion and mobilizing intellectual resources. Methods and methodology. In this article, the features of digital citizenship are considered through the following theoretical and methodological foundations: digital citizenship in the concept of a network club; generational theory of being digital citizens; digital citizenship as a value system of user strategies; the administrative plane of obtaining the legal status of a citizen in the network. Analysis. Synergy effects from joint activities of government, business and civil society institutions in the implementation of digital citizenship are extremely important. In connection with the creation of digital citizenship infrastructure in the Russian Federation, obtaining a digital profile of a citizen is of particular importance. Particular attention is paid to the risk factors for digital citizenship. The need to develop trust bridges between government and society, where co-management contributes to the formation of a safe and comfortable environment in physical and digital spaces, is argued. Results. The authors proposed the concept of architecture for building digital citizenship, which consists of the phased implementation of digital services: 1) the introduction of platform solutions in the field of public administration: the provision of public services in digital format, the launch of the Public Services Portal of the Russian Federation; 2) an increase in the number of public services provided in the online format, the launch of the Unified Identification and Authentication System (ESIA); 3) the Russian Federations citizen's digital profile creation, the launch of digital super services at the ESIA website, the introduction of an electronic passport of a citizen of the Russian Federation. It is concluded that the digital citizenship has new end-to-end communication capabilities, coupled with the extraterritoriality of processes. It is proved that digital citizenship is a fundamental right in the digital age. Digital literacy and digital security stand out as important elements of digital citizenship.
\end{abstract}

Key words: social media, digital citizenship, digital citizen, civil Internet activism, digital profile.

Citation. Bronnikov I.A., Karpova V.V. Digital Citizenship in the Russian Federation: Political Risks and Prospects. Vestnik Volgogradskogo gosudarstvennogo universiteta. Seriya 4. Istoriya. Regionovedenie. Mezhdunarodnye otnosheniya [Science Journal of Volgograd State University. History. Area Studies. International Relations], 2021, vol. 26, no. 3, pp. 123-133. (in Russian). DOI: https://doi.org/10.15688/jvolsu4.2021.3.11

\section{ЦИФРОВОЕ ГРАЖДАНСТВО В РОССИЙСКОЙ ФЕДЕРАЦИИ: ПОЛИТИЧЕСКИЕ РИСКИ И ПЕРСПЕКТИВЫ}

\author{
Иван Алексеевич Бронников \\ Московский государственный университет им. М.В. Ломоносова, г. Москва, Российская Федерация
}




\section{ПОЛИТИЧЕСКИЙ ПРОЦЕСС В СОВРЕМЕННОЙ РОССИИ}

\section{Виктория Вадимовна Карпова}

Форум молодых политологов России «Дигория», г. Москва, Российская Федерация; Московский государственный университет им. М.В. Ломоносова, г. Москва, Российская Федерация

Аннотация. Реалии современного общества отражают запрос науки на понимание, объяснение и сценирование структурных трансформаций политического процесса цифрового характера. Гражданская интернет-активность приобретает неиерархичные формы и опережает технологические практики, применяемые государством. Внедряясь в современный политический процесс, сетевые организационные структуры позволяют формировать прочные горизонтальные связи, выступая инструментом аккумулирования общественного мнения, координации гражданских инициатив и мобилизации интеллектуальных ресурсов. Крайне важным являются синергетические эффекты от совместной деятельности органов власти, бизнеса и институтов гражданского общества в вопросах внедрения цифрового гражданства, так как соуправление и сетевое сотрудничество способствуют формированию безопасной и комфортной среды в физическом и цифровом пространствах. В связи с созданием инфраструктуры цифрового гражданства в Российской Федерации получение цифрового профиля гражданина приобретает особую значимость. Авторами предложена концепция архитектуры построения цифрового гражданства, которая заключается в поэтапном внедрении цифровых сервисов: 1) внедрение платформенных решений в сферу государственного управления: предоставление государственных услуг в цифровом формате, запуск Единого портала государственных услуг; 2) увеличение количества предоставляемых государственных услуг в онлайн-формате, запуск Единой системы идентификации и аутентификации (ЕСИА); 3) создание цифрового профиля гражданина РФ, запуск цифровых суперсервисов на площадке ЕСИА, внедрение электронного паспорта гражданина РФ. Вклад авторов. И.А. Бронниковым и В.В. Карповой определены стержневые характеристики построения архитектуры цифрового гражданства, которые связаны с развитием следующих параметров: «государство как платформа», широкомасштабное использование электронного голосования, внедрение цифрового профиля гражданина и электронного паспорта. И.А. Бронников раскрыл новые возможности сквозной коммуникации и выделил важные элементы цифрового гражданства (цифровая грамотность и цифровая безопасность). В.В. Карпова исследовала факторы риска цифрового гражданства.

Ключевые слова: социальные медиа, цифровое гражданство, цифровой гражданин, гражданский интернет-активизм, цифровой профиль.

Цитирование. Бронников И. А., Карпова В. В. Цифровое гражданство в Российской Федерации: политические риски и перспективы // Вестник Волгоградского государственного университета. Серия 4, История. Регионоведение. Международные отношения. - 2021. - Т. 26, № 3. - С. 123-133. - DOI: https://doi.org/10.15688/ jvolsu4.2021.3.11

Введение. Развитие современных информационно-коммуникационных технологий (далее - ИКТ) снижает традиционные барьеры гражданского участия и переводит взаимодействие государства и акторов гражданского общества в цифровой формат. При вариативности позиций в основу института цифрового гражданства большинство ученых вкладывают статус гражданина. Объект исследования - политические риски и перспективы инфраструктуры цифрового гражданства. Цель исследования состоит в выявлении особенностей построения востребованной архитектуры цифрового гражданства, а также в определении потенциальных рисков и угроз внедрения цифрового гражданства в РФ.

В свое время Э. Тоффлер говорил, что развитие ИКТ позволит любому гражданину без посредников принимать активное участие в решении насущных проблем. Современные сетевые технологии не только создают площадки гражданских практик, но также дают возможности и инструменты для повышения их эффективности, так как позволяют легко сочетать институционализированные формы общественного участия с неформальными интернет-практиками.

Возрастающая роль онлайн-пространства в нынешних социополитических процесcax $[11 ; 26 ; 27]$ способствует глобальной цифровой трансформации, в частности становлению концепции цифрового гражданства [1; 9; 20] как новой грани гражданского участия в постинформационном обществе.

В западных научных журналах поле исследований онлайн-активизма достаточно на- 
сыщено эмпирической информацией [23; 24; 27]. В отечественных работах проблематика цифрового активизма носит фрагментарный характер [4; 11], что связано как с недавней практикой синхронизации взглядов с зарубежными исследованиями, так и с российскими особенностями самоорганизации граждан в сетевых сообществах. Особо следует отметить, что некоторые исследователи [4] считают, что социальные сети не являются триггером гражданского и политического активизма. Наряду с этим в научном дискурсе имеется и противоположная позиция $[3 ; 4 ; 11]$. Цифровая трансформация общественных отношений способствовала снижению эффективности устоявшихся моделей гражданского участия, что особенно ярко проявляется в молодежной среде $[5 ; 13 ; 16]$.

Современный цифровой мир многогранен и изменчив. Сейчас уже не вызывает удивления тот факт, что в мире насчитывается более 3,8 млрд пользователей социальных сетей [20], а в 2020 г. среднестатистический человек тратит на медиапотребление $40 \%$ времени в период бодрствования, или 6 ч 43 мин (для сравнения в России данный показатель еще выше - 7 ч 17 мин). Отличительной чертой становится также социально-медийный детокс, или использование социальных сетей «по делу» вместо парадигмы «новая искренность». Однако возникают проблемные аспекты иного типа и формата. Например, проблема цифрового неравенства внутри самой сети. Так, одни граждане являются полноправными участниками цифрового мира, а другие просто потребляют заранее подготовленный контент (консьюмтариат).

Методы и методология. В рамках понятия «цифровое гражданство» как нового явления для пространства политической науки целесообразно выделить ключевые теоретико-методологические основы:

1) Цифровое гражданство в кониепuии сетевого клуба. Наиболее широкая трактовка включения в категорию «цифровых граждан» принадлежит американским топменеджерам Google Дж. Коэну и Э. Шмидту [7]. Кибероптимистическая гипотеза аналитиков Google заключается в том, что граждане, вкусившие все плюсы и возможности новых реалий медиапотребления, будут обладать значительным потенциалом политического влияния, используя максимальную выгоду от цифровых коммуникаций и цифровой эпохи в целом. Кроме того, сетевые взаимодействия позволяют приобрести пользовательский статус для решения насущных проблем.

2) Поколенческая теория причисления $\kappa$ ичирровым гражданам [19]. Масштабное развитие информационных технологий привело к различиям в социализации индивидов. М. Пренски отмечает наличие определенного разрыва между поколением «цифровых аборигенов», чья социализация совпала с массовым распространением цифровых технологий и более старшей когортой «цифровых иммигрантов», родившихся до цифровой эпохи [25]. Основная гипотеза заключается в том, что границы между поколениями «цифровых аборигенов» и «цифровых иммигрантов» со временем нивелируются, а «цифровая мудрость», рассматриваемая как набор навыков критического освоения информации в виртуальном пространстве, начинает играть первостепенную роль.

А. Вромен, исследуя мобилизацию цифровых граждан и общую гибридизацию медиасферы, утверждает, что радикальные эффекты в социальных медиа связаны с деятельностью нового поколения сетевых акторов [28]. Неудивительно поэтому, что Л. Эррера нынешнюю молодежь относит к поколению цифрового бунта [18]. Помимо этого, важное значение для идентификации цифровых граждан имеют количественные и качественные характеристики онлайн-поведения.

3) Цифровое гражданство как иенностная система пользовательских стратегий. Концептуализация феномена цифрового гражданства была произведена американским политологом К. Моссбергер [22]. Под цифровым гражданством в авторской интерпретации подразумевается системное и эффективное участие в онлайн-жизни, а цифровая грамотность и культура цифрового гражданства раскрывает принадлежность к цифровым гражданам. Важно отметить, что К. Моссбергер и соавторы интерпретировали цифровое гражданство как ценностную систему, обеспечивающую ответственное и безопасное поведение в интернет-среде с учетом многообразия возможных пользовательских страте- 


\section{ПОЛИТИЧЕСКИЙ ПРОЦЕСС В СОВРЕМЕННОЙ РОССИИ}

гий. При этом цифровое гражданство проецируется в трех векторах: политическом, общественном и экономическом. Участие в общественной жизни рассматривается через политическое онлайн-влияние, а трансформация системы «государство - гражданское общество» позволяет выстроить прямой диалог, что является важной задачей цифрового правительства.

Цифровое гражданство может использоваться для определения ответственного поведения пользователей в мире цифровых технологий. К примеру, концепция М. Рибла [26] строится на трех принципах (уважение, просвещение и защита), состоящих в совокупности из девяти элементов цифрового гражданства. Е.В. Бродовская выделяет определенный примат институциональных составляющих цифровизации над социокультурными, что приводит к рассинхронизации процессов создания цифровой инфраструктуры [1].

4) Административная плоскость получения правового статуса гражданина в сети. По существу речь идет о получении правового статуса гражданина в «онлайне» (к примеру, приобретение цифрового профиля гражданина как дополнительного элемента impartial and effective offline good governance). В связи с созданием инфраструктуры цифрового гражданства в РФ получение цифрового профиля гражданина приобретает особую значимость.

Таким образом, несмотря на многоаспектность трактовок феномена цифрового гражданства, наиболее релевантным для целей статьи считаем концептуализированный подход К. Моссбергер и соавторов.

Анализ. В рамках данной работы построение архитектуры цифрового гражданства будет рассматриваться в двух направлениях. Во-первых, с точки зрения инициативы сверху. Принципиальным отличием этого вида активности является тот факт, что каналы взаимодействия созданы и контролируются самим государством, то есть граждане принимают существующие правила и действуют согласно заложенному властью плану. И, во-вторых, с точки зрения инициативы снизу (Grassroots). Это низовые движения граждан с целью выражения своих прав, требований, интересов и мнений в цифровом формате. Не последнюю роль в вопросе интенсификации цифрового гражданства в повседневность сыграли республиканские практики типа делиберации, которые позволяют принимать совместные управленческие решения в процессе инклюзивного публичного обсуждения.

Следует подчеркнуть, что проблематика гражданского активизма в России находится в зоне повышенного внимания в последние годы. В докладах Общественной палаты РФ отмечается готовность гражданских активистов к переходу от контроля к участию в реализации стратегических проектов. Более того, диалоговые интернет-практики между государством и гражданским обществом в России обладают значительным потенциалом общественного участия граждан, что связано с мотивационной составляющей постматериалистических ценностей.

При этом интернет-активизм достаточно тесно связан с проявлением ичифровой гражданственности. Обширный пул гражданских интернет-активностей достаточно подробно рассматривается в работах $[4 ; 7 ; 11$; $12 ; 14 ; 28]$. Практики гражданского интернетактивизма несут перспективный импульс в преодолении «коммуникационного провала» между гражданским обществом и властью. При этом гражданская интернет-активность приобретает неиерархичные формы и опережает технологические практики, применяемые государством. Внедряясь в современный политический процесс, сетевые организационные структуры позволяют формировать прочные горизонтальные связи, выступая инструментом аккумулирования общественного мнения, координации гражданских инициатив и мобилизации интеллектуальных ресурсов.

Результаты. Построение архитектуры цифрового гражданства можно рассматривать сквозь призму предпосылки институционализированной рациональности. Инициатива ускоренного внедрения цифровых технологий заложена в Указе Президента РФ № 204 от 7 мая 2018 г. «О национальных целях и стратегических задачах развития Российской Федерации на период до 2024 года», а также в национальной программе «Цифровая экономика Российской Федерации», общий бюджет которой составляет 1634,9 млрд рублей. Перепроектирование и реинжиниринг процессов со- 
здают цифровые услуги [10], а стратегии цифровой трансформации подразумевают разнообразные модели взаимодействия в концепции платформенного инкрементализма. Основными элементами структуры цифрового правительства является наличие транзакционно интегрированных правительственных порталов, совместное использование данных в государственном секторе, наличие инфраструктуры на государственном и межведомственном уровнях.

В последние годы достигнуты солидные показатели степени развития цифровой архитектуры. В 2019 г. РФ заняла 23-е место в рейтинге цифровых экономик мира, 14-е место по доступу к цифровым технологиям и сервисам [15]. При этом $47 \%$ россиян позитивно оценивают влияние новых технологий на общество. Однако наряду с положительной динамикой наблюдается глобальная тенденция кризиса к цифровому доверию (прежде всего защита персональных данных). Мировой показатель составляет $45 \%$, в России процент доверия остановился на уровне $29 \%$, а более $44 \%$ участников исследования осуществляет попытки по сокращению «цифровых следов» - данных, которыми респонденты готовы делиться в глобальной сети.

В 2019 г. Минстрой России совместно с учеными из МГУ им. М.В. Ломоносова разработали индекс цифровизации городского хозяйства «IQ городов». Индекс включает в себя 47 показателей и позволяет определить базовый уровень цифровизации городского хозяйства и эффективность решений, внедряемых регионами и городами. На сегодняшний момент самые высокие показатели у Москвы, Казани, Санкт-Петербурга и Нижнего Новгорода.

В то же время новые горизонты цифрового общества и общий тренд технологизации социального пространства формируют ряд рисков, связанных с цифровизацией общественного пространства [2]. В этой связи И.А. Василенко выделяет парадоксы цифровизации городского пространства: невысокий уровень творческих и талантливых людей; ограничение свободы человека с развитием цифровых технологий; вопросы конфиденциальности и личной тайны «умных домов», потенциально превращающихся в стеклянные аква- риумы; дегуманизация общественного пространства (виртуальное зазеркалье Фромма); «цифровое слабоумие» молодежи. Для предотвращения опасностей цифрового общества в российских реалиях необходима гуманитарная экспертиза при внедрении смарт-технологий в городскую жизнь.

Существенно то, что цифровой формат взаимодействия с органами государственной власти рассматривается странами-лидерами кибертрансформации как необходимое условие для повышения конкурентоспособности. Основной задачей цифрового правительства выступает формирование структурного каркаса административных процессов на основе эффективного использования цифровых данных, платформ и их экосистем. При этом Россия входит в тройку лидеров по темпам роста использования цифровых услуг, а число пользователей госуслуг в электронном виде за 2018-2019 гг. превышает среднемировые показатели втрое. Более того, по оценке Similarweb (Law And Government) портал государственных услуг РФ является одним из лучших в мире, занимая 2-е место по посещаемости [17]. Количество зарегистрированных пользователей превышает отметку в 100 млн, а на апрель 2020 г. доступно в электронном виде более 29 тыс. услуг [6]. В планы по развитию цифровой инфраструктуры входит запуск 23 суперсервисов и создание цифрового профиля гражданина РФ.

Цифровой профиль [8] представляет собой обновленную систему идентификации и аутентификации, содержащую сведения о гражданах и юридических лицах, призванную упростить процессы обмена данными между индивидами, бизнесом и государством. В качестве основной платформы для построения цифрового профиля рассматривается ЕСИА (Единая система идентификации и аутентификации). На февраль 2020 г. в системе было зарегистрировано 100 млн человек [6]. На наш взгляд, позитивной тенденцией внедрения технологии может стать быстрота получения различного вида услуг и проактивность предложений для граждан, способствующая переходу от модели «запросов» к полноценному предоставлению комплексных услуг.

Одновременно с этим возникновение цифровых профилей приведет к постановке 


\section{ПОЛИТИЧЕСКИЙ ПРОЦЕСС В СОВРЕМЕННОЙ РОССИИ}

вопроса относительно формирования цифровых прав и обязанностей граждан, а само государство перейдет к гибридному типу существования, совмещая виртуальное и физическое пространства. Тем не менее, объединяя все юридически значимые сведения и «цифровое досье» граждан, консолидированный сбор метаданных может привести к рискам централизованного управления обществом со стороны государства. Экспертное сообщество также отмечает, что у системы «одного окна» имеются уязвимые места: использование данных в корыстных целях коммерческим сектором или попытки репликации китайской системы «рейтинга общественной надежности».

Между тем, как следует из официальных данных, РФ намерена отказаться от бумажных паспортов взамен на электронные аналоги. Электронный паспорт будет давать доступ к цифровому профилю гражданина РФ, а основной акцент сделан на использовании биометрических электронных ID карт с возможностью электронного голосования. В этой связи проведение голосования через дистанционные формы выступает новым вектором отмены «избирательного рабства» в рамках механизма «мобильный избиратель». Московский экспериментальный опыт электронного голосования дал импульс для развития электоральных процедур в целом, обозначил политические риски и «болевые точки» функционирующей системы, что позволит в перспективе эффективно масштабировать опыт на избирательные кампании 2021 и 2024 годов. Отметим, что по данным доклада ВЦИОМ [9] у россиян имеется сформированный запрос на внедрение и качественное развитие электронного голосования. Однако не стоит форсировать события без решения множественных проблемных аспектов (монополизация рынка цифровых услуг, избыточное государственное регулирование онлайн-пространства, дефицит работников цифровой сферы и пр.), так как это может привести к формированию «воронки недоверия» у граждан.

Переходя к вопросу построения архитектуры цифрового гражданства «сверху», можно выделить следующую схему внедрения:

1) внедрение платформенных решений в сферу государственного управления: предоставления государственных услуг в цифровом формате, запуск Единого портала государственных услуг (ЕПГУ);

2) увеличение предоставляемых государственных услуг в онлайн-формате, запуск ЕСИА;

3) создание цифрового профиля гражданина РФ, запуск цифровых суперсервисов на площадке ЕСИА, внедрение электронного паспорта россиянина.

Цифровое гражданство является дополнением к национальному гражданству и может привести к развитию облачных сообществ (так называемое глобальное гражданство), основанных на технологиях блокчейна и виртуальных отношениях, что позволит минимизировать контроль со стороны государства и сформировать гибкие «правила игры». В перспективе это приведет к тому, что облачные сообщества смогут выступать элементом, улучшающим различные многоуровневые измерения гражданства, осуществляя управление ценностями и данными цифрового мира, впоследствии оказывая влияние на принятие политических решений в реальном мире [24].

Отдельного внимания заслуживают работы, посвященные созданию виртуальных наций [14] с новыми формами гражданского участия. С течением времени виртуальные нации могут конкурировать не столько с аналогичными облачными сообществами, сколько с национальными государствами. Стоит отметить, что подобные проблески нового мира в части экспериментов по построению виртуальных наций на основе цифрового гражданства наблюдаются уже сегодня. Так, с одной стороны, существуют призывы полностью заменить национальное государство (суверенная цифровая нация Bitnation), а с другой - использовать гармоничное дополнение существующих государственных институтов (внедрение цифрового гражданства).

По мнению исследователя Р. Баубека [12, р. 261-266], имеются значительные проблемные аспекты, связанные с определением и указанием своей национальной принадлежности. Так, облачные политические сообщества являются продолжением реально существующих объединений, а выполнение основных государственных функций не представляется возможным при переходе к рыночному формату гражданства. Учитывая резкий 
рост мобильности, значительно расширяются возможности внетерриториальных политических сообществ. При этом монопольные интернет-гиганты Google или Facebook берут на себя ряд функций, принадлежавших ранее национальным государствам. К примеру, формирование пользовательского интереса, навязывание повестки дня, идентификация личности, что в перспективе может привести к превращению онлайн-пользователей в корпоративных цифровых граждан. Более того, продолжает расти уровень обеспокоенности пользователей относительно конфиденциальности данных [20]. Современные алгоритмы анализа онлайн следов позволяют сформировать ландшафт цифровых инфопотоков и спрогнозировать политический выбор [21], а специально созданные таргетированные сообщения только усиливают эффект. Более того, технологии искусственного интеллекта связаны с интересами политической элиты (так называемая «дейтократия»), имеющей доступ к цифровой инфраструктуре. Сегодняшний формат цифрового неравенства - разный уровень доступа к цифровым следам и дифференцированное владение компетенциями в использовании больших данных (Big Data) [3]. Одновременно с этим возникновение цифровых профилей приведет к формированию прав и обязанностей граждан в цифровом пространстве вкупе с общей гибридизацией государства.

Вопросы цифровой трансформации были обострены и актуализированы кризисными факторами 2020 г., где роль ключевого триггера выполнил новый штамп коронавирусной инфекции. Эпидемия коронавируса вынуждает человечество сделать шаг в сторону новой цифровой реальности. По всему миру вводятся различные технологические продукты для контроля за передвижением и поведением граждан в период пандемии: мобильные приложения в Великобритании и Нидерландах, GPS-трекеры и данные телефонов в Южной Корее, браслеты в Гонконге, Франции и Италии, цифровые пропуска в России.

Установленные в период пандемии ограничения не имеют сроков применения и с теоретической точки зрения могут стать новой нормой повседневности, а введенные меры провоцируют дискуссии о «виртуальном паноптикуме». Исходя из этого, представляет- ся важным выстраивать не барьеры избыточной системы цифрового контроля за гражданами под соусом «борьбы с пандемией», а сосредоточиться на построении доверительных мостов между властью и обществом, где добровольная отчетность и сотрудничество наряду с информированной и сознательной общественностью главной ценностью ставит безопасность в физическом и цифровом пространствах.

Выводы. Общественное развитие и технологические изменения порождают новые формы и явления в политическом процессе, формирующие альтернативные подходы к устройству политической жизни. Цифровая трансформация открыла обширный пул возможностей и одновременно существенных политических рисков для взаимодействия, формируя новые формы и практики гражданского и политического цифрового участия, где традиционные подходы к политическому и гражданскому участию становятся опосредованными онлайн-пространством.

Общее усложнение структуры и процессов в обществе, обострение социальных противоречий, политических конфликтов и уровня сетевизации общественных сквозных взаимодействий существенно повышает степень неопределенности ситуаций, в которых принимаются политико-управленческие решения. Именно поэтому для того, чтобы преодолеть «коммуникативный провал» между акторами гражданского общества и государством, сегодня необходимо внедрение цифрового гражданства в современные реалии, что позволит структурировать неиерархическое пространство цифровых взаимодействий. Высшее руководство РФ воспринимает цифровизацию не только с точки зрения социально-политических рисков, но и как инструмент экономического роста.

Стержневые характеристики построения архитектуры цифрового гражданства связаны, прежде всего, с развитием системы «государство как платформа» и внедрением цифрового профиля гражданина. Значимой проблемой развития цифровой инфраструктуры является слабая защита персональных данных пользователей, что выражается в желании граждан максимально обезопасить свои интернет-следы. В этой связи культура цифрового граж- 
данства должна пониматься как неотъемлемый элемент постинформационного общества с понятными нормативно-правовыми и этическими нормами и порядками. Полноценная реализация цифрового гражданства будет способствовать увеличению количества и качества гражданских инициатив, что в конечном итоге приведет к общему повышению качества человеческого капитала и использования его как фактора социально-экономического развития в РФ.

\section{СПИСОК ЛИТЕРАТУРЫ}

1. Бродовская, Е. В. Цифровые граждане, цифровое общество и цифровая гражданственность /Е. В. Бродовская// Власть. - 2019. - Т. 27, №4. - С. 6569. - DOI: https://doi.org/10.31171/vlast.v27i4.6587.

2. Василенко, И. А. «Умный город» в цифровом обществе 5.0: социально-политические и гуманитарные риски цифровизации общественного пространства / И. А. Василенко // Власть. - 2019. T. 27, № 5. - C. 67-73. - DOI: https://doi.org/10.31171/ vlast.v27i5.6721.

3. Володенков, С. В. Влияние технологий интернет-коммуникаций на современные общественно-политические процессы: сценарии, вызовы и акторы / С. В. Володенков // Мониторинг общественного мнения: экономические и социальные перемены. - 2019. - № 5 . - C. 341-364. - DOI: https://doi.org/ 10.14515/monitoring.2019.5.16.

4. Гражданский активизм в России: мотивация, ценности и формы участия / В. В. Петухов, Р. Э. Бараш, Н. Н. Седова, Р. В. Петухов // Власть. 2014. - Т. 22, № 9. - С. 11-19.

5. Гражданственность российских старшеклассников: взгляд молодых ученых / под общ. ред. А. В. Селезневой. - М. : Аквилон, 2020. - 132 с.

6. Исследование «Экономика Рунета / Экосистема Цифровой экономики России». - Электрон. текстовые дан. - Режим доступа: http:// www.экономикарунета.pф/ (дата обращения: 09.06.2020). - Загл. с экрана.

7. Коэн, Д. Новый цифровой мир. Как технологии меняют жизнь людей, модели бизнеса и понятие государств / Д. Коэн, Э. Шмидт. - М. : Манн, Иванов и Фербер, 2013. - 368 с.

8. Проект Федерального закона № 747513-7 «О внесении изменений в отдельные законодательные акты (в уточнения процедур идентификации и аутентификации)» // Система обеспечения законодательной деятельности. - Электрон. текстовые дан. - Режим доступа: https://sozd.duma.gov.ru/bill/747513-7 (дата обращения: 09.06.2020). - Загл. с экрана.
9. Цифровое голосование в России: первые эксперименты и перспективы // Всероссийский центр изучения общественного мнения (ВЦИОМ). Электрон. текстовые дан. - Режим доступа: https:// wciom.ru/index.php?id $=236 \&$ uid $=9997 \&$ fbclid $=$ IwAR1sp1IRRMltpYaVOdLvAR4EdjMFQgk_Ow4hdE GoPcT7PxTZgwx-Kfxz7DA (дата обращения: 07.06.2020). - Загл. с экрана.

10. Цифровое правительство 2020: перспективы для России // Группа Всемирного Банка. - Электрон. текстовые дан. - Режим доступа: http:// documents.vsemirnyjbank.org/curated/ru/690171 468181130951/pdf/105318-RUSSIAN-WP-PUBLICDigital-Government-2020.pdf (дата обращения: 23.06.2020). - Загл. с экрана.

11. Якимец, В. Н. Гражданское участие, межсекторное партнерство и интернет-технологии публичной политики / В. Н. Якимец, Л. И. Никовская // Социальные и гуманитарные знания. - 2019. T. 5, № 3. - C. 208-223.

12. Bauböck, R. Debating Transformations of National Citizenship / R. Bauböck // Springer Nature. 2018. - 342 p. - DOI: https://doi.org/10.1007/978-3-31992719-0.

13. Bennett, W. L. Changing citizenship in the Digital Age / W. L. Bennett // Civic life online: Learning how digital media can engage youth. Cambridge : The MIT Press, 2008. - P. 1-24. - DOI: https://doi.org/ 10.1162/dmal.9780262524827.001.

14. De Filippi, P. Citizenship in the era of blockchainbased virtual nations / P. De Filippi // Debating Transformations of National Citizenship. - Springer, Cham, 2018. -P. 267-277.-DOI: https://doi.org/10.1007/ 978-3-319-92719-0 48.

15. Digital Society Index 2019 // Dentsu Aegis Network. - Electronic text data. - Mode of access: https://www.dentsuaegisnetwork.com/reports/dsi 2019 (date of access: 07.06.2020). - Title from screen.

16. Eynon, R. A Typology of Young People's Internet Use: Implications for Education / R. Eynon, L.-E. Malmberg // Computers and Education. - 2011.Vol. 56, № 3. - P. 585-595. - DOI: https://doi.org/ 10.1016/j.compedu.2010.09.020.

17. Gosuslugi.ru Analytics - Market Share Stats \& Traffic Ranking // Website Traffic Statistics \& Analytics - SimilarWeb. - Electronic text data. Mode of access: https://www.similarweb.com/ website/gosuslugi.ru (date of access: 17.06.2020). Title from screen.

18. Herrera, L. Youth and Citizenship in the Digital Age: A View from Egypt / L. Herrera // Harvard Educational Review. - 2012. - Vol. 82, № 3. - P. 333352. - DOI: https://doi.org/10.4324/9780203747575-9.

19. Howe, N. Generations: The History of America's Future, 1584 to 2069 / N. Howe, W. Strauss. New York : Harper Collins, 1992. -544 p. 
20. Kemp, S. Digital 2020: 3.8 Billion people use social media / S. Kemp // Global Socially-Led Creative Agency. - Electronic text data. - Mode of access: https://wearesocial.com/blog/2020/01/digital-2020-3-8billion-people-use-social-media (date of access: 04.06.2020). - Title from screen.

21. Kosinski, M. Private traits and attributes are predictable from digital records of human behavior / M. Kosinski, D. Stillwell, Th. Graepel // Proceedings of the National Academy of Sciences of the United States of America. - 2013. - Vol. 110, № 15. - P. 5802 5805. - DOI: https://doi.org/10.1073/pnas.1218772110.

22. Mossberger, K. Digital Citizenship: The Internet, Society, and Participation / K. Mossberger, C. J. Tolbert, R. S. McNeal. - Cambridge, MA : The MIT Press, 2008. - 221 p. - DOI: https://doi.org/ 10.1080/19331680802290972.

23. Obar, J. A. Advocacy 2.0: An Analysis of How Advocacy Groups in the United States Perceive and Use Social Media as Tools for Facilitating Civic Engagement and Collective Action / J. A. Obar, P. Zube, C. Lampe // Journal of Information Policy. - 2012. Vol. 2. - P. 1-25. - DOI: https://doi.org/10.2139/ ssrn. 1956352.

24. Orgad, L. The Future of Citizenship: Global and Digital - A Rejoinder / L. Orgad // Debating Transformations of National Citizenship. - Springer, Cham, 2018. - P. 353-358. - DOI: https://doi.org/ 10.1007/978-3-319-92719-0_61.

25. Prensky, M. Digital Natives, Digital Immigrants Part 1 / M. Prensky // On the Horizon. MCB University Press, 2001. - Vol. 9, № 5. - P. 1-6. DOI: https://doi.org/10.1108/10748120110424816.

26. Ribble, M. Digital Citizenship for Educational Change / M. Ribble // Kappa Delta Pi Record. - 2012. Vol. 48 (4). - P. 148-151. - DOI: https://doi.org/10.1080/ 00228958.2012 .734015 .

27. Theocharis, Y. Stimulating citizenship or expanding entertainment? The effect of Facebook on adolescent participation / Y. Theocharis, E. Ouintelier //New Media \& Society. - 2016. - Vol. 18, № 5. - P. 817 836. - DOI: https://doi.org/10.1177/1461444814549006.

28. Vromen, A. Digital Citizenship and Political Engagement / A. Vromen // Digital Citizenship and Political Engagement. - London : Palgrave Macmillan, 2017. - P. 9-49. - DOI: https://doi.org/10.1057/978-1137-48865-7.

\section{REFERENCES}

1. Brodovskaja E.V. Cifrovye grazhdane, cifrovoe obshhestvo i cifrovaja grazhdanstvennost' [Digital Citizens, Digital Society and Digital Citizenship]. Vlast', 2019, vol. 27, no. 4, pp. 65-69. DOI: https://doi.org/10.31171/vlast.v27i4.6587.
2. Vasilenko I.A. «Umnyj gorod» v cifrovom obshhestve 5.0: social'no-politicheskie i gumanitarnye riski cifrovizacii obshhestvennogo prostranstva [Prospects of Forming a Digital Society: Socii-Political and Humanitarian Risks of Digitization of Public Space]. Vlast', 2019, vol. 27, no. 5, pp. 6773. DOI: https://doi.org/10.31171/vlast.v27i5.6721.

3. Volodenkov S.V. Vlijanie tehnologij internetkommunikacij na sovremennye obshhestvennopoliticheskie processy: scenarii, vyzovy i aktory [Influence of Internet Communication Technologies on Contemporary Social and Political Processes: Scenarios, Challenges, and Actors]. Monitoring obshhestvennogo mnenija: jekonomicheskie i social'nye peremeny [Monitoring of Public Opinion: Economic and Social Changes], 2019, no. 5, pp. 341-364. DOI: https://doi.org/ 10.14515/monitoring.2019.5.16.

4. Petuhov V.V., Barash R.Je., Sedova N.N., Petuhov R.V. Grazhdanskij aktivizm v Rossii: motivacija, cennosti i formy uchastija [Civic Activism in Russia: Motivation, Values and Forms of Participation]. Vlast', 2014, vol. 22, no. 9, pp. 11-19.

5. Selezneva A.V., ed. Grazhdanstvennost' rossijskih starsheklassnikov: vzgljad molodyh uchenyh [Citizenship of Russian High School Students: The View of Young Scientists]. Moscow, Akvilon Publ., 2020. 132 p.

6. Issledovanie "Jekonomika Runeta/ Ekosistema Tsifrovoy ekonomiki Rossii» ["The Economy of Runet" Research]. URL: http://www. jekonomika runeta.rf/ (accessed 9 June 2020).

7. Kojen D., Shmidt Je. Novyj cifrovoj mir. Kak tehnologii menjajut zhizn' ljudej, modeli biznesa $i$ ponjatie gosudarstv [The New Digital Age: Reshaping the Future of People, Nations and Business]. Moscow, Mann, Ivanov i Ferber Publ., 2013. 368 p.

8. Proekt Federal'nogo zakona № 747513-7 "O vnesenii izmenenij $v$ otdel'nye zakonodatel'nye akty ( $v$ utochnenija procedur identifikacii $i$ autentifikacii)» [On Amending Certain Laws (Regarding Clarification of Identification and Authentication Procedures)]. URL: https://sozd. duma.gov.ru/bill/747513-7 (accessed 9 June 2020).

9. Cifrovoe golosovanie v Rossii: pervye jeksperimenty i perspektivy [Digital Voting in Russia: First Experiments and Prospects]. VCIOM [Russian Public Opinion Research Center]. URL: https://wciom. $\mathrm{ru} / \mathrm{index} \cdot \mathrm{ph}$ ? $\mathrm{id}=236 \& \mathrm{uid}=9997 \& \mathrm{fbclid}=$ IwAR1sp1IRRMltpYaVOdLvAR4EdjMFQgk_Ow4 hdEGoPcT7PxTZgwx-Kfxz7DA (accessed 7 June 2020).

10. Cifrovoe pravitel'stvo 2020: perspektivy dlja Possii [Digital Government 2020: Prospects for Russia]. URL: http://documents.vsemirnyjbank.org/ curated/ru/690171468181130951/pdf/105318RUSSIAN-WP-PUBLIC-Digital-Government-2020.pdf (accessed 23 June 2020). 


\section{ПОЛИТИЧЕСКИЙ ПРОЦЕСС В СОВРЕМЕННОЙ РОССИИ}

11. Jakimec V.N., Nikovskaja L.I. Grazhdanskoe uchastie, mezhsektornoe partnerstvo i internettehnologii publichnoj politiki [Civil Participation, Intersectoral Partnership and Internet Technologies of Public Policy]. Social'nye i gumanitarnye znanija [Social and Humanitarian Knowledge], 2019, vol. 5, no. 3, pp. 208-223.

12. Bauböck R. Debating Transformations of National Citizenship. Springer Nature, 2018. 342 p. DOI: https://doi.org/10.1007/978-3-319-92719-0.

13. Bennett W.L. Changing Citizenship in the Digital Age. Civic Life Online: Learning How Digital Media Can Engage Youth. Cambridge, The MIT Press, 2008, pp. 1-24. DOI: https://doi.org/10.1162/dmal. 9780262524827.001.

14. De Filippi P. Citizenship in the Era of Blockchain-Based Virtual Nations. Debating Transformations of National Citizenship. Springer, Cham, 2018, pp. 267-277. DOI: https://doi.org/10.1007/ 978-3-319-92719-0 48.

15. Digital Society Index 2019. Dentsu Aegis Network. URL: https:/www.dentsuaegisnetwork.com/ reports/dsi_2019 (accessed 7 June 2020).

16. Eynon R., Malmberg L.-E. A Typology of Young People's Internet Use: Implications for Education. Computers and Education, 2011, vol. 56, no. 3, pp. 585-595. DOI: https://doi.org/10.1016/j. compedu.2010.09.020.

17. Gosuslugi.ru Analytics - Market Share Stats \& Traffic Ranking. Website Traffic Statistics \& Analytics - SimilarWeb. URL: https:// www.similarweb.com/website/gosuslugi.ru (accessed 17 June 2020).

18. Herrera L. Youth and Citizenship in the Digital Age: a View from Egypt. Harvard Educational Review, 2012, vol. 82, no. 3, pp. 333-352. DOI: https://doi.org/ 10.4324/9780203747575-9.

19. Howe N., Strauss W. Generations: The History of America's Future, 1584 to 2069. New York, Harper Collins, $1992.544 \mathrm{p}$.

20. Kemp S. Digital 2020: 3.8 Billion People use Social Media. Global Socially-Led Creative Agency.
URL: https://wearesocial.com/blog/2020/01/digital2020-3-8-billion-people-use-social-media (accessed 4 June 2020).

21. Kosinski M., Stillwell D., Graepel Th. Private Traits and Attributes are Predictable from Digital Records of Human Behavior. Proceedings of the National Academy of Sciences of the United States of America, 2013, vol. 110, no. 15, pp. 5802-5805. DOI: https://doi.org/10.1073/pnas. 1218772110.

22. Mossberger K., Tolbert C.J., McNeal R.S. Digital Citizenship: The Internet, Society, and Participation. Cambridge, MA, The MIT Press, 2008, 221 p. DOI: https://doi.org/10.1080/ 19331680802290972.

23. Obar J.A., Zube P., Lampe C. Advocacy 2.0: An Analysis of How Advocacy Groups in the United States Perceive and Use Social Media as Tools for Facilitating Civic Engagement and Collective Action. Journal of Information Policy, 2012, vol. 2, pp. 1-25. DOI: https://doi.org/10.2139/ssrn.1956352.

24. Orgad L. The Future of Citizenship: Global and Digital - A Rejoinder. Debating Transformations of National Citizenship. Springer, Cham, 2018, pp. 353-358. DOI: https://doi.org/10.1007/978-3-31992719-0 61.

25. Prensky M. Digital Natives, Digital Immigrants Part 1. On the Horizon. MCB University Press, 2001, vol. 9, no. 5, pp. 1-6. DOI: https://doi.org/10.1108/ 10748120110424816.

26. Ribble M. Digital Citizenship for Educational Change. Kappa Delta Pi Record, 2012, vol. 48 (4), pp. 148-151. DOI: https://doi.org/10.1080/ 00228958.2012.734015.

27. Theocharis Y., Ouintelier E. Stimulating Citizenship or Expanding Entertainment? The Effect of Facebook on Adolescent Participation. New Media \& Society, 2016, vol. 18, no. 5, pp. 817-836. DOI: https:/ /doi.org/10.1177/1461444814549006.

28. Vromen A. Digital Citizenship and Political Engagement. Digital Citizenship and Political Engagement. London, Palgrave Macmillan, 2017, pp. 949. DOI: https://doi.org/10.1057/978-1-137-48865-7. 


\section{Information About the Authors}

Ivan A. Bronnikov, Candidate of Sciences (Politics), Associate Professor, Department of Russian Politics, Deputy Dean, Faculty of Political Science, Lomonosov Moscow State University, Leninskie Gory, 1, 119991 Moscow, Russian Federation, ivbronn@gmail.com, https://orcid.org/0000-0002-8277-0839

Victoriya V. Karpova, Program Director, Digoria Forum of Young Political Scientists of Russia, Krasnopresnenskaya Emb., 12, 123610 Moscow, Russian Federation; Postgraduate Student, Department of Public Policy, Faculty of Political Science, Lomonosov Moscow State University, Leninskie Gory, 1, 119991 Moscow, Russian Federation, v.karpova@digoriya.ru, https://orcid.org/0000-0003-2532-1241

\section{Информация об авторах}

Иван Алексеевич Бронников, кандидат политических наук, доцент кафедры российской политики, заместитель декана факультета политологии, Московский государственный университет им. М.В. Ломоносова, Ленинские горы, 1, 119991 г. Москва, Российская Федерация, ivbronn@gmail.com, https://orcid.org/0000-0002-8277-0839

Виктория Вадимовна Карпова, программный директор, Форум молодых политологов России «Дигория», Краснопресненская набережная, 12, 123610 г. Москва, Российская Федерация; аспирант кафедры государственной политики факультета политологии, Московский государственный университет им. М.В. Ломоносова, Ленинские горы, 1, 119991 г. Москва, Российская Федерация, v.karpova@digoriya.ru, https://orcid.org/0000-0003-2532-1241 